\title{
p53R2 as a novel prognostic biomarker in nasopharyngeal carcinoma
}

\author{
Jiewei Chen ${ }^{1,2 \dagger}$, Shuman $\mathrm{Li}^{1 \dagger}$, Yongbo Xiao ${ }^{1,2 \dagger}, X^{\prime}$ uan Zou ${ }^{3}$, Xinke Zhang ${ }^{1,2}$, Mingshu Zhu ${ }^{1,2}$, Muyan Cai ${ }^{1,2^{*}}$ \\ and Dan $\mathrm{Xie}^{1,2^{*}}$
}

\begin{abstract}
Background: p53R2 is a target of p53 gene, which is essential for DNA repair, mitochondrial DNA synthesis, protection against oxidative stress, chromosomal instability, chronic inflammation and tumorigenesis. This study is aimed to investigate the expression of ribonucleotide reductase (RR) subunit p53R2 in nasopharyngeal carcinoma and its significance in the prognosis.
\end{abstract}

Methods: The expression levels of p53R2 in 201 patients with NPC were examined by immunohistochemical assay. The correlations of p53R2 expression and clinicopathological features of nasopharyngeal carcinoma patient were analysed by chi-square test. The Kaplan-Meier survival analysis and Cox multivariate regression model were used to analyze the prognostic significance of the patients with NPC.

Results: Immunohistochemical results showed that p53R2 was positively expressed in 92.5\% (186/201) of nasopharyngeal carcinoma and the high expression rate was 38.3\% (77/201). Further analysis observed that the negative correlation between expression of p53R2 and pT status had statistical significance $(P<0.05)$. Kaplan-Meier survival analysis found that the mean survival time of patients with high expression of p53R2 was 143.32 months, while the patients with low expression level of p53R2 was 121.63 months $(P<0.05)$. Cox regression analysis suggested that p53R2 protein expression could be used as an independent prognostic factor for nasopharyngeal carcinoma $(P<0.05)$.

Conclusions: This study drew a conclusion that p53R2 could be used as a prognostic biomarker indicative of the favorable outcome for patients with nasopharyngeal carcinoma.

Keywords: Nasopharyngeal carcinoma, p53R2, Immunohistochemistry, Prognosis

\section{Background}

Nasopharyngeal carcinoma (NPC) is the malignant cancer occurring on the top and lateral wall of nasopharynx cavity [1], which is prevalent in southeast Asia especially in southern China. Most of the NPC patients are diagnosed at the stage of III or IV, and the 5 years survival rate is $50 \%-60 \%$ [2]. It has been proved that EpsteinBarr virus infection, genetic susceptibility, environmental factors, dysfunction of oncogenes or suppressor genes and life styles are all associated with NPC tumorigenesis [3]. The process of nasopharyngeal carcinoma from

\footnotetext{
* Correspondence: caimy@sysucc.org.cn; xiedan@sysucc.org.cn

${ }^{\dagger}$ Equal contributors

${ }^{1}$ Sun Yat-sen University Cancer Center ; State Key Laboratory of Oncology in South China; Collaborative Innovation Center for Cancer Medicine,

Guangzhou, China

Full list of author information is available at the end of the article
}

mucosal epithelium of the nasopharynx, to low-grade dysplastic epithelium, high-grade dysplastic epithelium, invasive and metastasis cancer involves in multiple genes alteration, for example, alleles loss on 3p, 9p, 11q, 13q, $14 \mathrm{q}, 16 \mathrm{q}$ and gained on chromosomes $8,12[4,5]$. p53R2 located on chromosome $8 \mathrm{q} 23.1$ is a target of p53 gene. When DNA is damaged, the cell cycle is blocked at G1 and G2 stage. Subsequently, p53R2 is upregulated and accumulated in the nuclear to provide dNTP to repair the damaged DNA [6, 7]. Different phenotypes of p53R2 have been found in various human cancers. In small cell lung cancer and esophageal cancer, high level of p53R2 expression has been shown to be a biomarker of tumor invasion and worse prognosis, which indicates p53R2 may be an oncogenic role in these cancers $[8,9]$. While in colorectal cancer, overexpression of p53R2 indicates a 
good outcome for the patients, suggesting that p53R2 may be a tumor suppressor [10, 11]. However, it's still unclear what's the expression status of p53R2 expression in NPC and its clinicopathological significance. Here we used IHC to evaluate the protein level of p53R2 in nasopharyngeal carcinoma tissues and apply the statistic analysis methods to identify the association between p53R2 and the prognostic significance of nasopharyngeal carcinoma.

\section{Methods}

\section{Patients and specimens}

In this study, 201 specimens of NPC in Sun Yat-sen University Cancer Center from January 2001 to October 2012 were collected. The cases selected were based on the following criteria: pathologically confirmed as nasopharyngeal cancer with available biopsy specimens for immunohistochemistry; no previous malignant disease or a second primary tumor; without radiotherapy, chemotherapy and surgery treatment history; completed follow-up data. Patients who had no complete clinical follow-up data or had died from other unknown reasons were excluded. The pTMN stage was defined based on the sixth edition TNM classification criteria established by the International Union Against Cancer (UICC, 2002). All the experiments done in this study were approved by the institute research medical ethics committee of Sun Yat-sen University.

\section{Immunohistochemistry (IHC)}

IHC was performed using standard EnVision method. The paraffin-embedded tissue blocks were cut into $3 \mu \mathrm{m}$ thick sequential sections, the slides were dried and deparaffinized in xylene, rehydrated through graded alcohol, immersed in 3\% hydrogen peroxide for $10 \mathrm{~min}$ to block endogenous peroxidase activity and antigen retrieved by pressure cooking for $3 \mathrm{~min}$ in citrate buffer $(\mathrm{pH}=6)$. Then the slides were incubated with 5\% BSA for $15 \mathrm{~min}$ to reduce nonspecific reaction. Subsequently, the slides were incubated with the rabbit monoclonal antibody anti-p53R2 (Abcam, ab154194, 1:400 dilution) for $50 \mathrm{~min}$ at $37{ }^{\circ} \mathrm{C}$. The slides were sequentially incubated with a secondary antibody (Envision, Dako, Denmark) for $30 \mathrm{~min}$ in the incubator at $37{ }^{\circ} \mathrm{C}$, and stained with DAB (3,3-diaminobenzidine). Finally, the sections were counterstained with Mayer's hematoxylin, dehydrated and mounted. A negative control was obtained by replacing the primary antibody with a normal rabbit IgG.

\section{IHC evaluation}

p53R2 staining was mainly observed at the cytoplasm, and the positively stained cells were brown or yellow.
Immune reactivity was scored by evaluating the number of positive cells and the positive intensity score: (i) The percentage of positive tumor cells: take 5 fields every slide to counter the percentage in $5 \%$ increments from 0 to $100 \%$ ( 0 indicates negative staining). (ii) Positive intensity score: negative (0), weak (1), moderate (2) and strong (3). (iii) The scores obtained from intensity and the proportion ( $0-300$ scores). We used the ROC curve to determine the cut-off value of p53R2 expression level in NPC. Two pathologists who were blind to the information of patients performed the scoring. If the results were different, then a third pathologist would participate to confirm the score.

\section{Statistical analysis}

SPSS software (version 21.0, SPSS, Chicago, IL) was used to operate the analysis. ROC analysis was performed to determine the cut-off value for p53R2 expression. We applied $X^{2}$ test to evaluate the relationship between p53R2 and NPC patients' clinicopathological characteristics. Univariate analysis was performed by the Kaplan-Meier. Cox regression analysis was employed to identify the independent prognostic factor. Two-tailed $P$ value less than 0.05 was considered statistically significant.

\section{Results}

p53R2 expression in NPC tissues examined by IHC

The positive expression of p53R2 by IHC analysis in nasopharyngeal carcinoma was primarily a cytoplasm pattern (Fig. 1) and the positive expression rate was $92.5 \%(186 / 201)$.

\section{Cut-off value for $\mathrm{p} 53 \mathrm{R} 2$ expression}

ROC curve was used to identify the cut-off for p53R2. The point with both maximum sensitivity and specificity was chosen as the cut-off point [12]. Area under the curve (AUC) and $P$ value were shown in Table 1 . The sensitivity and specificity for each clinicopathological feature were plotted (Fig. 2). Therefore, we used the survival status as a state variable. The ROC curve analysis revealed that the cut-off value of the expression of p53R2 protein was $150(P<0.05)$.

\section{Association of p53R2 expression with NPC patients' clinicopathological features}

Further analysis showed that expression of p53R2 was significantly correlated with $\mathrm{T}$ stage (Table 2, $P=$ 0.043 ) and there was no significant association between p53R2 expression and other clinicopathological features, such as patient sex, age, lymph node metastasis, clinical stage, therapeutic regimen, relapse (Table 2, $P>0.05$ ). As shown in this table, high-level 


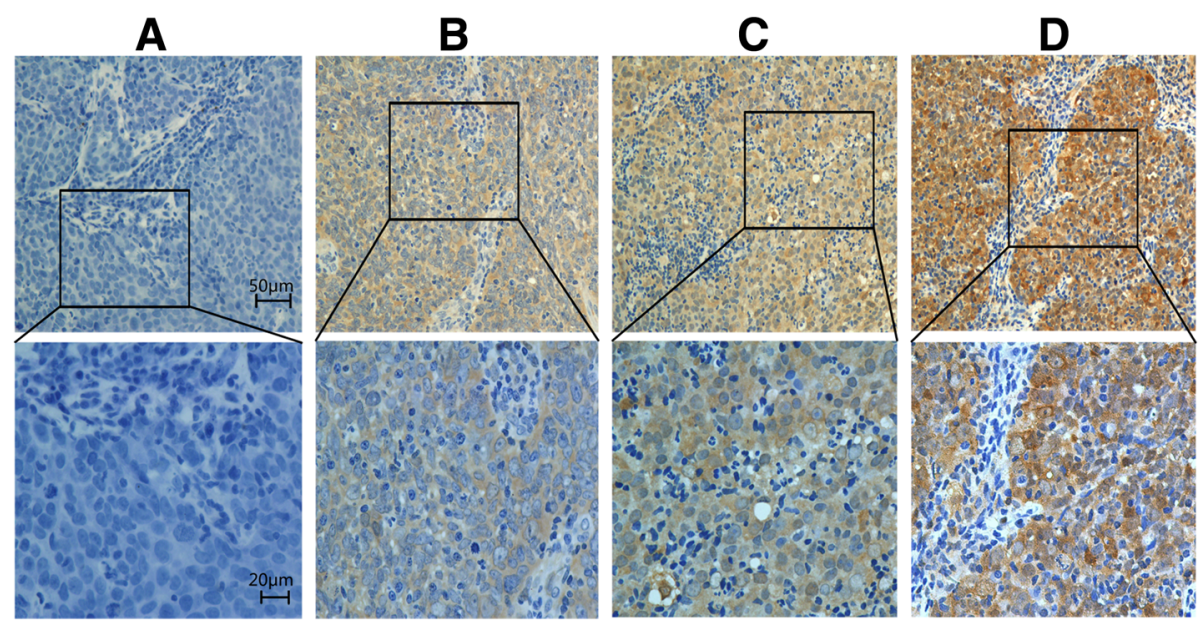

Fig. 1 Expression of p53R2 protein in NPC tissues. a, Negative expression; b, Low expression; c, Moderate expression; d, Strong expression

of p53R2 was observed in $48.4 \%$ of stage $\mathrm{T} 1+\mathrm{T} 2$ patients and in $33.6 \%$ of stage $\mathrm{T} 3+\mathrm{T} 4$ patients.

\section{The relationship between p53R2 expression status and clinicopathological characteristics and NPC patients' survival}

In this present study, the survival analysis showed that patients with high p53R2 expression had a better survival $(P=0.012$, Fig. 3a). To explore the prognostic factor for NPC, we calculated the influence of the clinicopathological features on the prognosis of NPC, the mean survival period of patients with clinical stage I-II (mean: 149.60 months) was longer than that with clinical stage III-IV (mean: 126.65 months) $(P=$ 0.021 , Fig. $3 \mathrm{~b})$. The mean overall survival period for patients with older age was shorter than that with younger age; the difference was statistically different $(P=0.010$, Fig. 3c). There was also a better survival for patients with stage T1 and T2 compared to patients with T3 and T4 $(P=0.038$, Fig. $3 \mathrm{~d})$. We also observed a significantly different survival rate between the patients with $\mathrm{N} 0$ and the patients with N1-3 $(P=0.048$, Fig. 3e). Recurrence was also found to be a significant prognostic factor for NPC ( $P<0.001$, Fig. 3f). All the detailed data were shown in Table 3.

Table 1 AUC operating characteristic curve for each clinicopathological feature

\begin{tabular}{lll}
\hline Feature & AUC $(95 \% \mathrm{Cl})$ & $P$ value $^{\mathrm{a}}$ \\
\hline T stage & $0.557(0.468-0.645)$ & 0.197 \\
$\mathrm{~N}$ stage & $0.591(0.469-0.712)$ & 0.124 \\
Survival status & $0.604(0.509-0.698)$ & 0.047 \\
Clinical stage & $0.515(0.405-0.624)$ & 0.776 \\
\hline
\end{tabular}

${ }^{\mathrm{a} C h i-s q u a r e ~ t e s t s ~}$
To investigate the impact of the p53R2 protein expression on the survival of NPC patients with different subgroups, further analysis was performed regarding p53R2 expression in subsets of NPC patients in different clinical stage, $\mathrm{pT}$ stage, $\mathrm{pN}$ stage. We observed that the expression of $\mathrm{p} 53 \mathrm{R} 2$ was a prognostic factor for stage $\mathrm{III}+\mathrm{IV}(P=0.015), \mathrm{pT} 3+\mathrm{T} 4(P=0.025), \mathrm{pN} 1+\mathrm{N} 2+\mathrm{N} 3$ $(P=0.012$, Fig. 4$)$.

\section{Independent prognostic factors for NPC patients}

The factors that had a significant difference in univariate analysis were further tested in the cox regression analysis, and the results suggested that p53R2 was an independent prognostic factor. Additionally, age and tumor relapse were independent prognostic factors for NPC patients as well (Table 4).

\section{The relationship between the expression of $\mathrm{p} 53 \mathrm{R} 2$ and the overall survival rate}

We utilized Kaplan-Meier analysis to evaluate the relationship between the expression of p53R2 and the survival rate of NPC patients (Table 3). In the high p53R2 expression group: this subgroup had a mean survival time of 143.32 months; the 5-year survival rate was $96.00 \%$, and the 10 -year survival rate was $82.90 \%$. However, in low p53R2 expression group: the mean survival period was 121.63 months, the 5-year survival rate was $83.20 \%$, and the 10 -year survival rate was $63.20 \%$ (Table 5).

\section{Discussion}

p53R2, a ribonucleotide reductase small subunit, belongs to the ribonucleotide reductase family. p53R2 offers dNTPs for DNA replication and repair [13]. p53R2 is essential for DNA repair, mitochondrial 

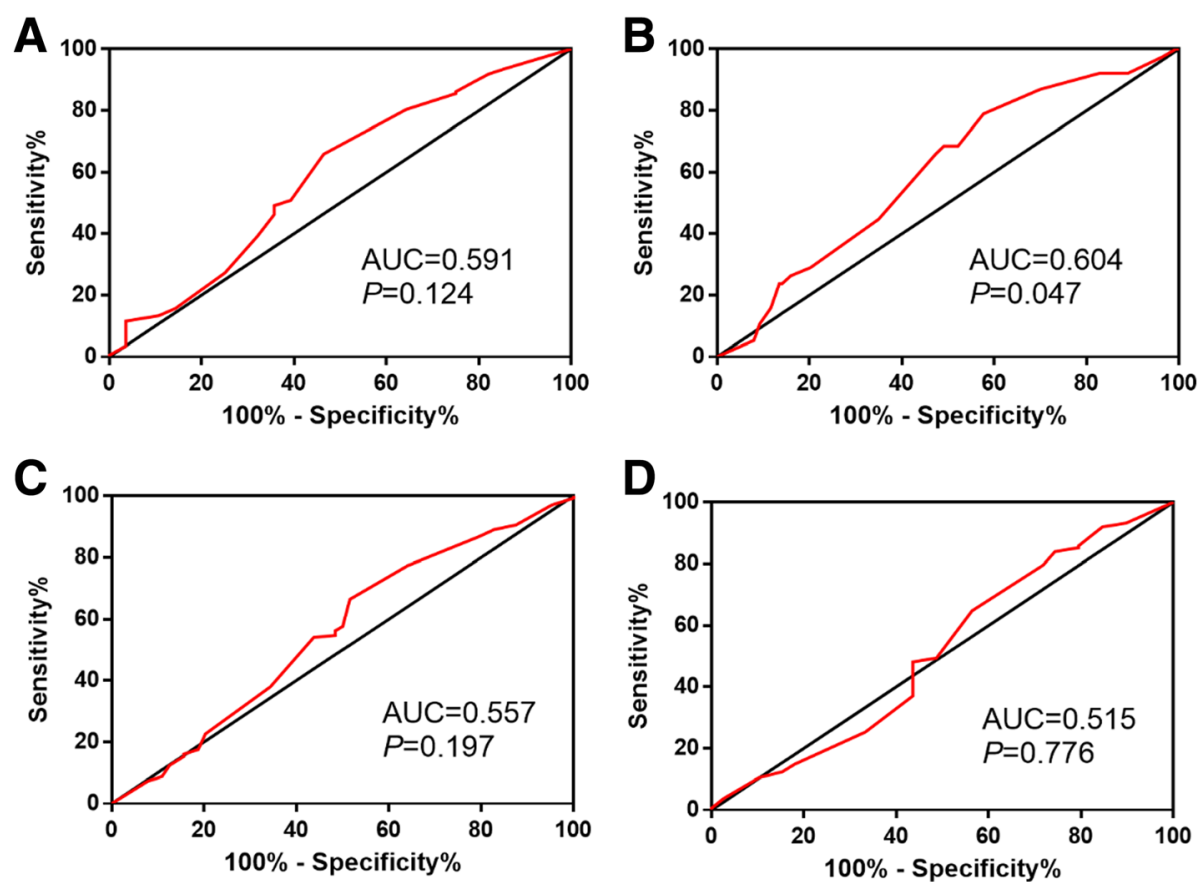

Fig. 2 ROC curve analysis was employed to determine the cut-off value for high p53R2 expression in NPC. The sensitivity and specificity for each outcome were plotted: pN status (a), survival outcome $(\mathbf{b}), \mathrm{pT}$ status $(\mathbf{c})$, clinical stage $(\mathbf{d})$

Table 2 Correlation between the p53R2 expression and clinicopathological variables in NPC patients

\begin{tabular}{|c|c|c|c|c|}
\hline \multirow[t]{2}{*}{ Variable } & \multicolumn{4}{|c|}{ Expression of p53R2 } \\
\hline & All cases & Low & High & $P$ value \\
\hline Gender & & & & 0.217 \\
\hline Female & 57 & 39 (68.4\%) & $18(31.6 \%)$ & \\
\hline Male & 144 & $85(59.0 \%)$ & $59(41.0 \%)$ & \\
\hline Age & & & & 0.593 \\
\hline$\leq 45.89^{\mathrm{a}}$ & 104 & $66(63.5 \%)$ & $38(36.5 \%)$ & \\
\hline$>45.89$ & 97 & $58(59.8 \%)$ & $39(40.2 \%)$ & \\
\hline Clinical stage & & & & 0.450 \\
\hline$|-| \mid$ & 39 & $22(56.4 \%)$ & $17(43.6 \%)$ & \\
\hline III-IV & 162 & $102(63.0 \%)$ & $60(37.0 \%)$ & \\
\hline T stage & & & & 0.043 \\
\hline $\mathrm{T} 1+\mathrm{T} 2$ & 64 & $33(51.6 \%)$ & $31(48.4 \%)$ & \\
\hline $\mathrm{T} 3+\mathrm{T} 4$ & 137 & $91(66.4 \%)$ & $46(33.6 \%)$ & \\
\hline N stage & & & & 0.469 \\
\hline No & 28 & 19 (67.9\%) & $9(32.1 \%)$ & \\
\hline $\mathrm{N} 1+\mathrm{N} 2+\mathrm{N} 3$ & 173 & $105(60.7 \%)$ & $68(39.3 \%)$ & \\
\hline Therapy $^{b}$ & & & & 0.205 \\
\hline Regimen 1 & 50 & $34(68.0 \%)$ & $16(32.0 \%)$ & \\
\hline Regimen 2 & 72 & $46(63.9 \%)$ & $26(36.1 \%)$ & \\
\hline Regimen 3 & 31 & $14(45.2 \%)$ & $17(54.8 \%)$ & \\
\hline Regimen 4 & 48 & $30(62.5 \%)$ & $18(37.5 \%)$ & \\
\hline Relapse & & & & 0.543 \\
\hline Yes & 30 & $20(66.7 \%)$ & $10(33.3 \%)$ & \\
\hline No & 171 & $104(60.8 \%)$ & $67(39.2 \%)$ & \\
\hline
\end{tabular}

${ }^{\mathrm{a}}$ mean age; ${ }^{\mathrm{b}}$ Regimen 1, radiation therapy;Regimen 2, chemoradiotherapy; Regimen 3 , induction + radiation therapy; Regimen 4, induction + chemoradiotherapy
DNA synthesis, protection against oxidative stress, chromosomal instability, chronic inflammation and tumorigenesis $[7,14,15]$. Recent study has found that p53R2 point mutation in HCT116 (a colorectal cancer cell line) could lead to ribonucleotide reductase (RR) activity attenuation and dysfunction of DNA repair [16]. Another study also indicated that in nontransformed cells, p53R2 was critical for maintaining mtDNA and repairing UV damaged DNA during quiescence [17].

Herein, we estimated the protein status of p53R2 in 201 NPC specimens by IHC. The result demonstrated that p53R2 was positive in $92.5 \%$ of the NPC, and further analysis revealed a significant correlation between p53R2 expression and $\mathrm{pT}$ stage by chi-square test. Univariate Kaplan-Meier analysis indicated that the status of p53R2 expression have a significant impact on patient survival. Cox multivariate analysis found that p53R2 was an independent prognostic factor for NPC. Taken together, our results suggest that p53R2 expression is a reliable biomarker for prognosis of NPC.

There are a few reports about the relationship between p53R2 expression and the prognosis of human cancers. In a study on colorectal cancer, high-level of p53R2 expression indicated patients having a longer survival period and could be a favorable prognostic factor [10, 11]. In consistent with this study, our data show that p53R2 expression is negatively correlated with 


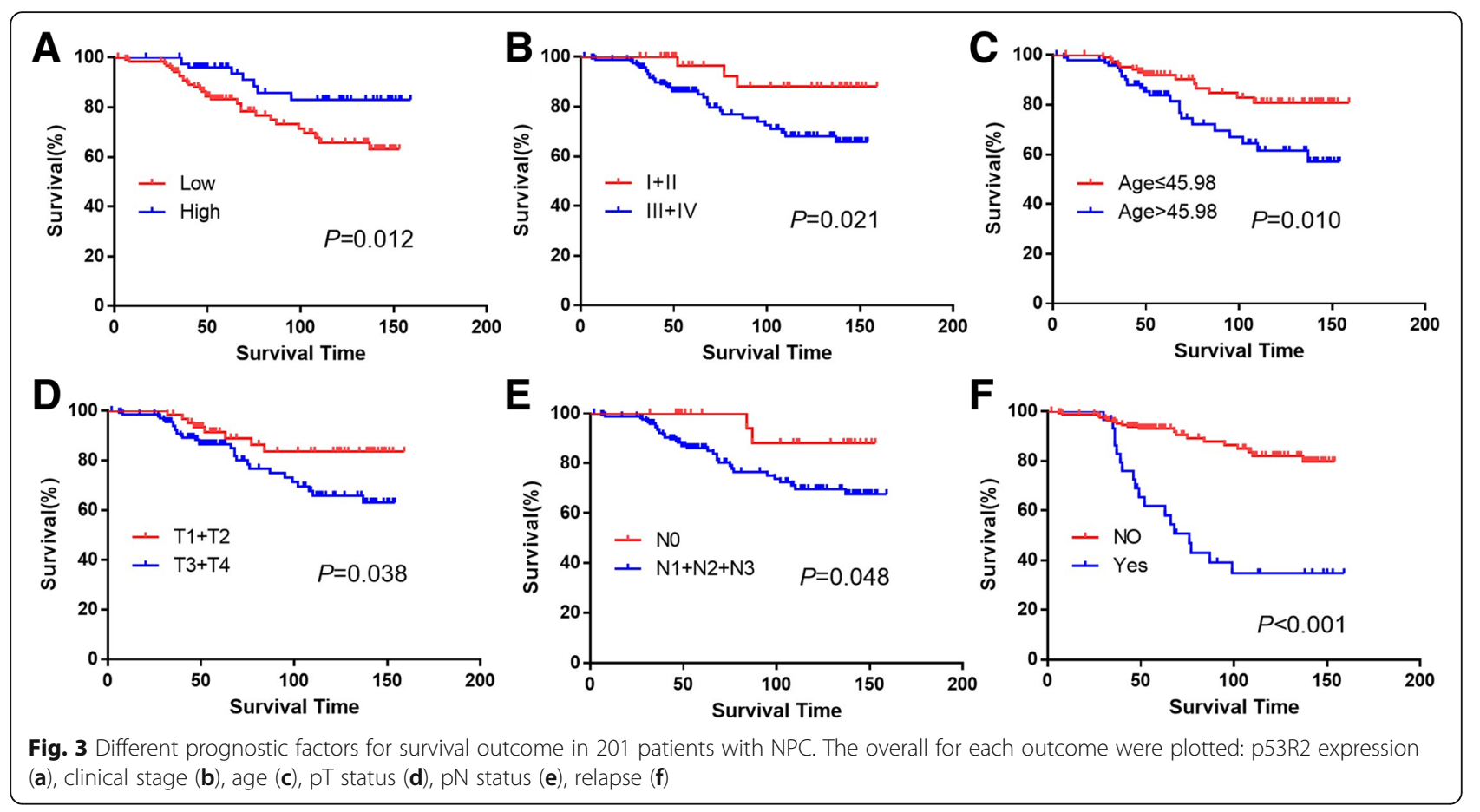

Table 3 Univariate survival analysis of different prognostic factors in 201 patients with NPC

\begin{tabular}{|c|c|c|c|c|}
\hline Variable & All cases & Mean survival (months) & Chi-square value & $P$-value \\
\hline Gender & & & 2.291 & 0.130 \\
\hline Male & 144 & 125.36 & & \\
\hline Female & 57 & 142.17 & & \\
\hline Age & & & 6.644 & 0.010 \\
\hline$\leq 45.89$ & 104 & 141.09 & & \\
\hline$>45.89$ & 97 & 118.95 & & \\
\hline Clinical stage & & & 5.310 & 0.021 \\
\hline$|-| I$ & 39 & 149.60 & & \\
\hline III-IV & 162 & 126.65 & & \\
\hline T stage & & & 4.323 & 0.038 \\
\hline $\mathrm{T} 1+\mathrm{T} 2$ & 64 & 142.54 & & \\
\hline $\mathrm{T} 3+\mathrm{T} 4$ & 137 & 123.32 & & \\
\hline $\mathrm{N}$ stage & & & 3.915 & 0.048 \\
\hline No & 28 & 146.06 & & \\
\hline $\mathrm{N} 1+\mathrm{N} 2+\mathrm{N} 3$ & 173 & 129.18 & & \\
\hline Therapy & & & 2.841 & 0.417 \\
\hline Regimen 1 & 50 & 122.82 & & \\
\hline Regimen 2 & 72 & 133.64 & & \\
\hline Regimen 3 & 31 & 127.82 & & \\
\hline Regimen 4 & 48 & 122.49 & & \\
\hline Relapse & & & 32.95 & 0.000 \\
\hline No & 171 & 138.15 & & \\
\hline Yes & 30 & 91.75 & & \\
\hline \multicolumn{5}{|l|}{ Expression } \\
\hline Low & 124 & 121.63 & 6.347 & 0.012 \\
\hline High & 77 & 143.32 & & \\
\hline
\end{tabular}

clinicopathological parameters and predicts a good outcome of NPC patients. Several previous studies reported that the positive staining of p53R2 examined by IHC, was observed dominantly in the cytoplasm of tumor cells, such as colon cancer, lung cancer and esophageal cancer $[9,18,19]$. In response to DNA damage stress, p53R2 will translocate from cytoplasm to nucleus [20]. M2B may translocate from the cytoplasm into the nucleus and allow dNTPs to initiate DNA synthesis in KB cells under physiological conditions [21].

More and more researchers show that p53R2 plays a key role in many biological processes and diseases including tumors. In the field of mitochondrial DNA disorder, RRM2B (encoding p53R2) is critical for mtDNA copy number and its dominant-negative or gain-of-function mutations is a major reason for mtDNA deletions and adPEO [22]. RRM2B-mousa had a renal dysgenesis and died of sever renal dysfunction at 14th week. So p53R2 is essential for the maintenance of normal renal function [23]. By contrast, there are some studies pointing out that p53R2 could promote the aggression of tumor $[8,9]$. p53R2 enhanced the invasion of cancer through E-cadherin/ $\beta$-catenin pathway [24]. In esophageal squamous cell cancer, p53R2 was significantly correlated with the infiltration depth, lymph node metastasis and poor prognosis [9]. p53R2 was also an adverse biomarker for the non-small cell lung cancer [8]. Moreover, p53R2 was further found to be correlated with lymph node metastasis, infiltration, general stage of the tumors in oral cancer and melanoma, while there is no 

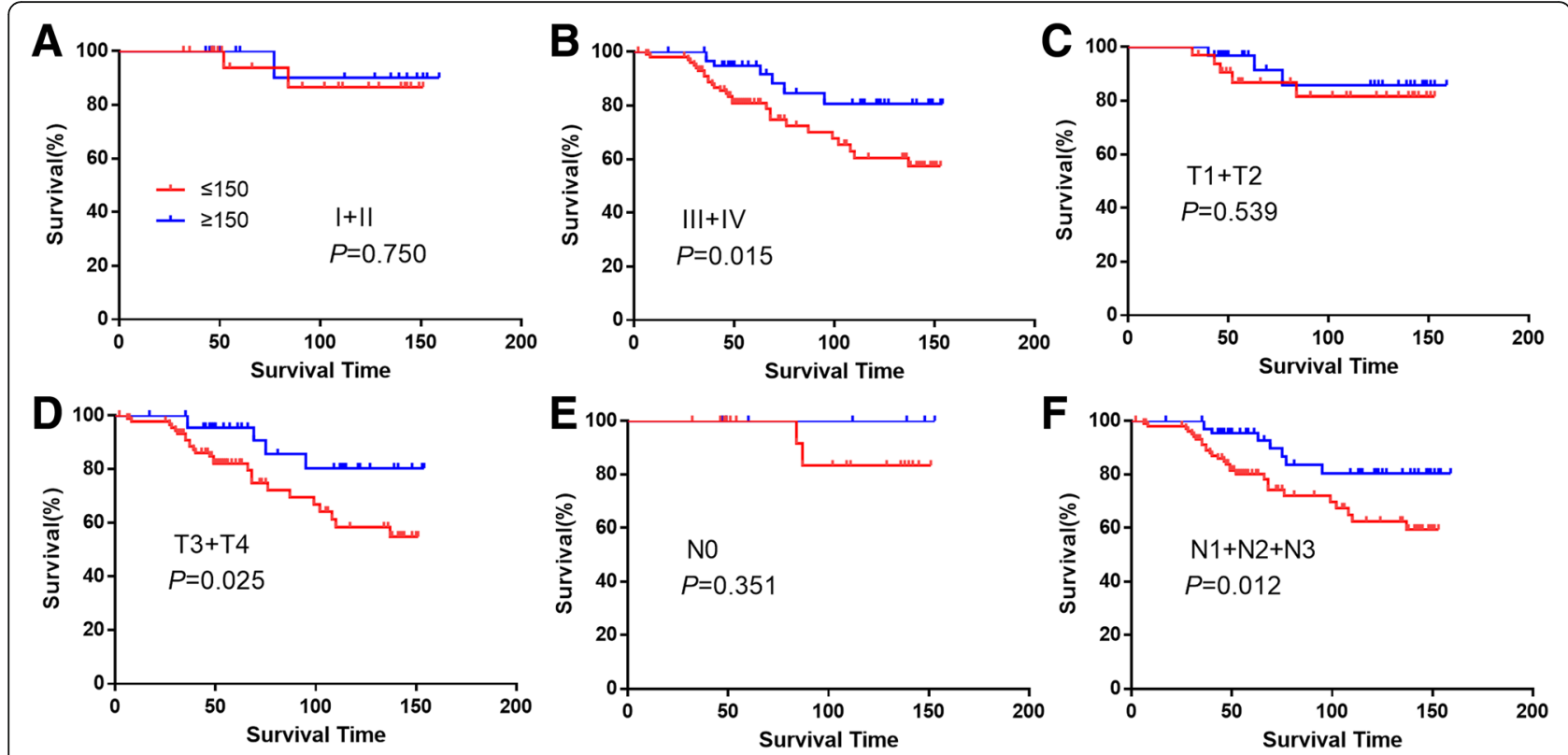

Fig. 4 Kaplan-Meier survival analysis of p53R2 expression in subsets of NPC patients with different clinical stage and pT/pN stage. Clinical stage I + II (a), Clinical stage III + IV (b), pT1 + T2 (c), pT3 + T4 (d), pN0 (e), pN1 + N2 + N3 (f)

relationship found between p53R2 and gastric cancer [25-27].

Our result showed that $\mathrm{p} 53 \mathrm{R} 2$ was a protective factor for the prognosis of nasopharyngeal carcinoma. These results may suggest p53R2 has the ability to repair the damaged DNA and inhibit tumor invasion. The expression of p53R2 is regulated by p53 in response to genotoxic stimulation, such as UV and chemical therapy (i.e., adriamycin) $[6,28]$, and the depletion of p53R2 can enhance the DNA damage caused by adriamycin [29]. After UV treatment, p53R2 was activated and bound to hRRM1 to form RR holoenzyme to synthesize dNTP induced by UV, and then damaged DNA was impaired in the p53mutant cell line PC3 [29]. DNMT/DNA adduct formation was a prerequisite for the activation of p53R2, and the p53R2 expression was induced by nucleosidebased DNMT inhibitors which could form DNA adducts [30]. It would take time to react to DNA damage after p53R2 induction, because p53R2 Ser72 phosphorylation by ataxia telangiectasia mutated

Table 4 Cox multivariate analysis of prognostic factors on overall survival

\begin{tabular}{llll}
\hline Variable & Hazards ratio & $95 \% \mathrm{Cl}^{*}$ & $P$ value \\
\hline Age $(>45.89$ vs. $\leq 45.89)$ & 3.14 & $1.58-6.25$ & 0.001 \\
Clinical stage (III-IV vs. I-II) & 3.27 & $1.00-10.67$ & 0.050 \\
Relapse (Yes vs. No) & 5.97 & $3.10-11.49$ & 0.000 \\
p53R2 expression (High vs. Low) & 0.39 & $0.18-0.85$ & 0.018 \\
\hline
\end{tabular}

${ }^{*} \mathrm{Cl}$, confidence interval;
(ATM) occurred within $30 \mathrm{~min}$ after genotoxic factors, and Ser72 phosphorylation by ATM was necessary for p53R2 stability and enduing resistance to DNA damage [13]. Besides, p53R2 dominant-negative or gain-of-function mutation was a major reason for mtDNA loss and mitochondrial disease [22]. Furthermore, a decreased p53R2 expression by siRNA significantly increased the cellular invasion potential in p53 mutant cell lines while the up-regulation of p53R2 could inhibit the tumor metastasis [31]. The different functions of p53R2 in different cancers indicated that p53R2 had two sides in tumorigenesis. Our study reveals that the protein level p53R2 is a novel factor for NPC patients with favorable prognosis. But the mechanism under the cell function and animal experiments need further exploration.

\section{Conclusions}

In a conclusion, the examination of p53R2 expression, by IHC, could be used as an additional effective tool in identifying those NPC patients at favourable outcome. Our study may provide the evidence that p53R2 is a potential therapeutic target for NPC.

Table 5 The expression of p53R2 for five-year survival rate and ten-year survival rate

\begin{tabular}{llll}
\hline $\begin{array}{l}\text { p53R2 } \\
\text { expression }\end{array}$ & $\begin{array}{l}\text { Mean survival time } \\
\text { (months) }\end{array}$ & $\begin{array}{l}\text { Five }- \text { year } \\
\text { survival rate (\%) }\end{array}$ & $\begin{array}{l}\text { Ten - year } \\
\text { survival rate (\%) }\end{array}$ \\
\hline Low & 121.63 & 83.20 & 63.20 \\
High & 143.32 & 96.00 & 82.90 \\
\hline
\end{tabular}




\section{Abbreviations}

AUC: Area under the curve; IHC: Immunohistochemistry; NPC: Nasopharyngeal Carcinoma; RR: Ribonucleotide Reductase

\section{Acknowledgements}

Not applicable.

\section{Funding}

This work was supported by the National Key R\&D Program of China (2017YFC1309000) and the Guangdong Natural Science who funded this work under the funds for distinguished young scholar (No. 2015A030306001)

\section{Availability of data and materials}

The dataset supporting the conclusions of this article is available on request from e-mail: xiedan@sysucc.org.cn

\section{Authors' contributions}

DX and MYC designed this research. JWC acquired and analyzed the data. JWC, S ML and YBX performed all the experiments and draft the manuscript, $X Z$, MSZ and XKZ collected the data. All authors have read and approved the final manuscript.

\section{Ethics approval and consent to participate}

The study was approved by the Institute Research Medical Ethics Committee of Sun Yat-sen University Cancer Center. No informed consent (written or verbal) was obtained for use of retrospective data from the patients within this study, most of whom were deceased, since this was not deemed necessary by the Ethics Committee, who waived the need for consent. All samples were anonymised.

\section{Consent for publication}

Not applicable.

\section{Competing interests}

The authors have declared that no competing interests exist.

\section{Publisher's Note}

Springer Nature remains neutral with regard to jurisdictional claims in published maps and institutional affiliations.

\section{Author details}

'Sun Yat-sen University Cancer Center ; State Key Laboratory of Oncology in South China; Collaborative Innovation Center for Cancer Medicine,

Guangzhou, China. ${ }^{2}$ Department of Pathology, Sun Yat-sen University Cancer Center, No. 651, Dongfeng East Road, Guangzhou 510060, China. ${ }^{3}$ Department of Pathology, The Sixth Affiliated Hospital, Sun Yat-sen University, Guangzhou 510655, China.

\section{Received: 30 July 2017 Accepted: 29 November 2017}

\section{Published online: 13 December 2017}

\section{References}

1. Chang ET, Adami HO. The enigmatic epidemiology of nasopharyngeal carcinoma. Cancer Epidemiol Biomark Prev. 2006;15(10):1765-77.

2. Fuyuhiro Y, Yashiro M, Noda S, Kashiwagi S, Matsuoka J, Doi Y, Kato Y, Hasegawa T, Sawada T, Hirakawa K. Upregulation of cancer-associated myofibroblasts by TGF- $\hat{I}^{2}$ from scirrhous gastric carcinoma cells. Br J Cancer. 2011;105(7):996.

3. Pierre Busson MD. Nasopharyngeal carcinoma. Curr Treat Options in Oncol. 2002;3(1):21-32.

4. Tanaka H, Arakawa H, Yamaguchi T, Shiraishi K, Fukuda S, Matsui K, Takei Y, Nakamura Y. A ribonucleotide reductase gene involved in a p53-dependent cell-cyclecheckpoint for DNA damage. Nature. 2000;404(6773):42-9.

5. Nakano K, Balint E, Ashcroft M, Vousden K. A ribonucleotide reductase gene is a transcriptional target of p53 and p73. Oncogene. 2000;19(37):4283-9.

6. Nakamura Y. Isolation of p53-target genes and their functional analysis. Cancer Sci. 2004:95(1):7.

7. Xue L, Zhou B, Liu X, Wang T, Shih J, Qi C, Heung Y, Yen Y. Structurally dependent redox property of ribonucleotide reductase subunit p53R2. Cancer Res. 2006;66(4):1900-5.
8. Uramoto H, Sugio K, Oyama T, Hanagiri T, Yasumoto K. P53R2, p53 inducible ribonucleotide reductase gene, correlated with tumor progression of nonsmall cell lung cancer. Anticancer Res. 2006;26(2A):983-8.

9. Okumura H, Natsugoe S, Yokomakura N, Kita Y, Matsumoto M, Uchikado Y, Setoyama T, Owaki T, Ishigami S, Aikou T. Expression of p53R2 is related to prognosis in patients with esophageal squamous cell carcinoma. Clin Cancer Res. 2006;12(12):3740-5.

10. Liu X, Lai L, Wang X, Xue L, Leora S, Wu J, Hu S, Zhang K, Kuo ML, Zhou L. Ribonucleotide reductase small subunit M2B prognoses better survival in colorectal cancer. Cancer Res. 2011;71(9):3202-13.

11. Liu X, Zhou B, Xue L, Yen F, Chu P, Un F, Yen Y. Ribonucleotide reductase subunits $M 2$ and p53R2 are potential biomarkers for metastasis of colon cancer. Clin Colorectal Cancer. 2007:6(5):374-81.

12. Cai MY, Zhang B, He WP, Yang GF, Rao HL, Rao ZY, QL W, Guan XY, Kung $\mathrm{HF}$, Zeng YX. Decreased expression of PinX1 protein is correlated with tumor development and is a new independent poor prognostic factor in ovarian carcinoma. Cancer Sci. 2010;101(6):1543.

13. Chang L, Zhou B, Hu S, Guo R, Liu X, Jones SN, Yen Y. ATM-mediated serine 72 phosphorylation stabilizes ribonucleotide reductase small subunit p53R2 protein against MDM2 to DNA damage. Proc Natl Acad Sci U S A. 2008; 105(47):18519-24

14. Bourdon A, Minai L, Serre V, Jais JP, Sarzi E, Aubert S, Chrétien D, de LP P-FV, Arakawa H. Mutation of RRM2B, encoding p53-controlled ribonucleotide reductase (p53R2), causes severe mitochondrial DNA depletion. Nat Genet. 2007;39(6):776-80.

15. Chang L, Guo R, Huang Q, Yen Y. Chromosomal instability triggered by Rrm2b loss leads to IL-6 secretion and plasmacytic neoplasms. Cell Rep. 2013:3(5):1389.

16. Yamaguchi T, Matsuda K, Sagiya $Y$, Iwadate M, Fujino MA, Nakamura $Y$, Arakawa H. p53R2-dependent pathway for DNA synthesis in a p53regulated cell cycle checkpoint. Cancer Res. 2001;61(22):8256-62.

17. Pontarin G, Ferraro P, Bee L, Reichard P, Bianchi V. Mammalian ribonucleotide reductase subunit p53R2 is required for mitochondrial DNA replication and DNA repair in quiescent cells. Proc Natl Acad Sci U S A. 2012;109(33):13302.

18. Liu X, Zhou B, Xue L, Yen F, Chu P, Un F, Yen Y. Ribonucleotide reductase subunits M2 and p53R2 are potential biomarkers for metastasis of colon cancer. Clin Colorectal Cancer. 2007:6(5):374.

19. Uramoto H, Sugio KT, Hanagiri T, Yasumoto K. P53R2, p53 inducible ribonucleotide reductase gene, correlated with tumor progression of nonsmall cell lung cancer. Anticancer Res. 2006;26(2A):983.

20. Devlin HL, Mack PC, Burich RA, Gumerlock PH, Kung HJ, Mudryj M, deVere White RW. Impairment of the DNA repair and growth arrest pathways by p53R2 silencing enhances DNA damage-induced apoptosis in a p53dependent manner in prostate cancer cells. Mol Cancer Res. 2008;6(5):808.

21. Liu X, Zhou B, Xue L, Shih J, Tye K, Qi C, Yen Y. The ribonucleotide reductase subunit $M 2 B$ subcellular localization and functional importance for DNA replication in physiological growth of KB cells. Biochem Pharmacol. 2005:70(9):1288-97.

22. Tyynismaa H, Ylikallio E, Patel M, Molnar MJ, Haller RG, Suomalainen A. A heterozygous truncating mutation in RRM2B causes autosomal-dominant progressive external ophthalmoplegia with multiple mtDNA deletions. Am J Hum Genet. 2009:85(2):290-5.

23. Kimura T, Takeda S, Sagiya Y, Gotoh M, Nakamura Y, Arakawa H. Impaired function of p53R2 in Rrm2b-null mice causes severe renal failure through attenuation of dNTP pools. Nat Genet. 2003;34(4):440.

24. Yanamoto S, Kawasaki G, Yamada S, Yoshitomi I, Yoshida H, Mizuno A. Ribonucleotide reductase small subunit p53R2 promotes oral cancer invasion via the E-cadherin/beta-catenin pathway. Oral Oncol. 2009;45(6): $521-5$.

25. Schepers H, Geugien M, Eggen BJ, Vellenga E. Constitutive cytoplasmic localization of p21(Waf1/Cip1) affects the apoptotic process in monocytic leukaemia. Leukemia. 2003;17(11):2113.

26. Yanamoto S, Iwamoto T, Kawasaki G, Yoshitomi I, Baba N, Mizuno A. Silencing of the p53R2 gene by RNA interference inhibits growth and enhances 5-fluorouracil sensitivity of oral cancer cells. Cancer Lett. 2005; 223(1):67

27. Matsushita S, Ikeda R, Fukushige T, Tajitsu Y, Gunshin K, Okumura H, Ushiyama M, Akiyama S, Kawai K, Takeda Y. p53R2 is a prognostic factor of melanoma and regulates proliferation and chemosensitivity of melanoma cells. J Dermatol Sci. 2012;68(1):19-24. 
28. Wang X, Zhenchuk A, Wiman KG, Albertioni F. Regulation of p53R2 and its role as potential target for cancer therapy. Cancer Lett. 2009;276(1):1-7.

29. Zhou B, Liu X, Mo X, Xue L, Darwish D, Qiu W, Shih J, Hwu EB, Luh F, Yen Y. The human ribonucleotide reductase subunit hRRM2 complements p53R2 in response to UV-induced DNA repair in cells with mutant p53. Cancer Res. 2003;63(20):6583-94.

30. Link PA, Baer MR, James SR, Jones DA, Karpf AR. p53-inducible ribonucleotide reductase (p53R2/RRM2B) is a DNA hypomethylationindependent decitabine gene target that correlates with clinical response in myelodysplastic syndrome/acute myelogenous leukemia. Cancer Res. 2008; 68(22):9358-66.

31. Liu X, Zhou B, Xue L, Shih J, Tye K, Lin W, Qi C, Chu P, Un F, Wen W. Metastasis-suppressing potential of ribonucleotide reductase small subunit p53R2 in human cancer cells. Clin Cancer Res. 2006;12(21):6337.

Submit your next manuscript to BioMed Central and we will help you at every step:

- We accept pre-submission inquiries

- Our selector tool helps you to find the most relevant journal

- We provide round the clock customer support

- Convenient online submission

- Thorough peer review

- Inclusion in PubMed and all major indexing services

- Maximum visibility for your research

Submit your manuscript at www.biomedcentral.com/submit
Biomed Central 